\title{
"Chcecie totalnej wolności słowa?" Kultura w Niemczech u progu lat dwudziestych (XXI wieku) wobec radykalizmu, wielokulturowości i konfliktów etnicznych. Próba rozpoznania problemów
}

\begin{abstract}
"Do you want total freedom of speech?" Culture in Germany at the end of the twenties (21st century) against radicalism, multiculturalism, and ethnic conflicts. An attempt to identify problems. This article attempts to present selected phenomena of contemporary German culture in the context of political radicalism, multiculturalism and ethnic conflicts. Starting with the criticism of the student protests of 1968 (using the example of the novel Örtlich betäubt by Günter Grass) and discourses on Europe in the early 1990s (Grass, Enzensberger), and ending with debates on freedom of expression, political correctness or "cancel culture" (Wallraff, Pirinçci, Nuhr, Eckhart), this article analyses the consequences of left- and right-wing radicalism, anti-Semitism and Islamism for literature and cabaret in Germany on selected examples.
\end{abstract}

Keywords: cancel culture, freedom of expression, political correctness, left and right radicalism

Wyobraźmy sobie ośmiu mężczyzn różniących się fizjonomią, budową ciała, postawą oraz ubiorem, dzięki któremu łatwo określić ich status majątkowy, pozycję

Adres do korespondencji: Instytut Nauk o Kulturze, ul. Jagiellońska 11, 85-067 Bydgoszcz. E-mail: k.okonski@ukw.edu.pl. 
społeczną i zawód. Stoją jeden za drugim, sprawiają wrażenie zmierzających w jednym kierunku, lecz widzą wyłącznie plecy poprzednika i zachowują bezpieczny dystans od siebie. Mimo ewidentnych podziałów można też dostrzec element integrujący tę grupę, choć nie tworzy on całości: są nim transparenty, które niosą uczestnicy tego dziwnego pochodu - czynią to bez większego przekonania, nie próbując nawet utrzymać ich równo. Trudno jednak nie zauważyć, że litery na transparentach tworzą napis R-E-P-U-B-L-I-K. To zbiorowy portret (choć nie ma na nim kobiet i dzieci) społeczeństwa republiki weimarskiej, nakreślony przez Thomasa Theodora Heinego na łamach czasopisma satyrycznego „Simplicissimus” w $1927 \mathrm{roku}^{1}$. Mimo swojej oszczędnej formy rysunek trafnie oddaje sens często używanej dziś przez historyków i publicystów formuły, opisującej Niemcy z okresu przed dojściem Hitlera do władzy jako „demokracji bez demokratów”2.

System parlamentarny, integracja z zachodnimi strukturami, wolności obywatelskie i azyl polityczny dla prześladowanych leżą wprawdzie u podstaw ustrojowych dzisiejszych Niemiec, lecz to właśnie społeczeństwo i jego elity, także kulturalne, wypełniają je treścią. Doświadczenia bońskiej, a później berlińskiej republiki pokazały, że mimo skandali politycznych (na przykład udział byłych nazistów w najwyższych władzach), kryzysów (rewolta studencka w 1968 roku, fala terroryzmu w latach siedemdziesiątych) ten kraj i jego obywatele, cytując noblistę Heinricha Bölla, „[...] nie [są] już Rzeszą Niemiecką, lecz Republiką Federalną Niemiec [...]. A RFN jako państwo w całej swojej historii od momentu powstania nie ma żadnego powodu, by odczuwać kompleks winy"'.

Życie kulturalne powojennych Niemiec nie było jednak wolne od odprysków narodowego socjalizmu: poczynając od (nadmiernie eksponowanych) antysemickich akcentów w działalności skupiającej czołówkę autorów niemieckojęzycznych Grupy $47^{4}$, poprzez spór między pisarzem Martinem Walserem a „papieżem krytyki literackiej” Marcelem Reich-Ranickim z rzekomymi antysemickimi uwagami pod adresem MRR w tle, kończąc na dyskusji wokół (krótkiej) służby Güntera Grassa w Waffen SS. Rozwój nowoczesnych form kultury, skierowanych do szerszego grona odbiorców oraz odejście z przyczyn naturalnych pokolenia zwanego „Flackhelfer-

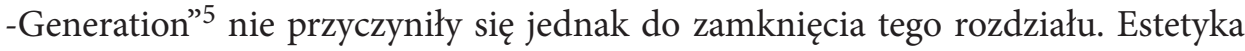

1 Por. T. T. Heine, „Sie tragen die Buchstaben der Firma-aber wer trägt den Geist?!”, Simplicissimus 1927, nr 51, strona tytułowa.

2 Por. m.in. H. Thoß, Demokratie ohne Demokraten? Die Innenpolitik der Weimarer Republik, Berlin 2008.

${ }^{3}$ H. Böll, „Ein neues Vokabolarium finden. Protokoll einer Pressekonferenz”, [w:] Verantwortlich für Polen?, red. F. Duve, K. Staeck, Reinbek bei Hamburg 1982, s. 9-17.

${ }^{4}$ S. Graefe, „Missachtung und Tabu. Eine Streitschrift zur Frage: Wie antisemitisch war die Gruppe 47?", Deutschlandfunk, 13.02.2003, https://www.deutschlandfunk.de/missachtung-und-tabueine-streitschrift-zur-frage-wie.700.de.html?dram:article_id=80782.

${ }^{5}$ Określenie pochodzi od nazwy personelu pomocniczego artylerii przeciwlotniczej, składającego się w końcowej fazie II wojny światowej głównie z chłopców. Por. m.in. K. Wigura, „Pokolenie pomocników artylerii. Habermas, Ratzinger, Luhmann i niemieckie spory”, Stan Rzeczy 2012, nr 1, s. $146-167$.

Miscellanea Posttotalitariana Wratislaviensia 8, 2020

(C) for this edition by CNS 
filmów Leni Riefenstahl jest jednym z najważniejszych elementów wizerunku odnoszącej międzynarodowe sukcesy grupy rockowej Rammstein (choć zespół odżegnuje się od związków z neonazizmem), a antysemickie treści pojawiają się nie tylko w utworach z kręgu Rechtsrock (prawicowego rocka), lecz także w twórczości raperów z „tłem migracyjnym” (by użyć określenia z niemieckich gazet). Adolf Hitler stał się bohaterem niemieckich komedii (Jojo Rabbit, Adolf H. - Ja wam pokażę), a krytyczna edycja jego Mein Kampf ukazała się w Niemczech po burzliwej debacie w 2016 roku.

Nawiązując do tytułu dzieła Ericha Fromma, którego przesłanie jest motywem przewodnim niniejszego tomu, należałoby zapytać o ucieczkę od wolności w czasach narastającego w Europie populizmu, odrodzenia nacjonalizmów, kryzysu migracyjnego, żywej pamięci o fali zamachów terrorystycznych na zlecenie tak zwanego Państwa Islamskiego, ale także reakcji na te zjawiska. Niemcy są krajem, którego historia i kultura skupiają w sobie wiele problemów zachodniego świata. To państwo wynalezienia druku i palenia książek, Adolfa Hitlera i Tomasza Manna (Marcel Reich-Ranicki), pokojowej rewolucji 1989, ale także inwigilacji społeczeństwa przez rozbudowaną sieć konfidentów Stasi. Owe tragiczne paradoksy niemieckich dziejów oraz wspomniana we wstępie polaryzacja ideologiczna w latach dwudziestych ubiegłego wieku pobudzają do refleksji nie tylko nad ucieczką od wolności w dzisiejszych Niemczech, lecz również nad strategiami jej obrony przed zakusami radykałów.

Niniejszy artykuł stanowi próbę wstępnego rozpoznania skutków, które dla współczesnej kultury niemieckiej niosą z sobą nacjonalizm i populizm, a z drugiej strony twitterowo-facebookowy, lecz realizowany też w świecie rzeczywistym, fenomen cancel culture czy mająca już pewną tradycję (i różnie definiowana) poprawność polityczna. O ile nawiązania w pierwszej części artykułu do wybranych dzieł lub postaci życia kulturalnego RFN mają charakter retrospektywny i są wprowadzeniem do rozważań na temat współczesności, to omówienie głównych wątków bieżących debat wokół występów publicznych pisarzy i artystów kabaretowych nie wyczerpuje z pewnością tematu i nie jest zamkniętym rozdziałem. Biorąc ponadto pod uwagę polskojęzyczną edycję niniejszego tomu, celowe wydaje się zaprezentowanie krytycznego przeglądu zjawisk w kulturze niemieckiej zamiast szczegółowych, lecz zbyt hermetycznych studiów danego przypadku. Może on tworzyć punkt wyjścia do komparatystycznych rozważań na temat wolności artystycznej w Polsce i w Niemczech oraz przybliżyć nieznane polskiemu czytelnikowi problemy, często zakorzenione w historii lub życiu społecznym i kulturalnym naszego zachodniego sąsiada.

Pierwszym impulsem do takich przemyśleń mógłby być w obecnych czasach obrachunek elit Republiki Federalnej z dziedzictwem studenckiej rewolty 1968 roku, która wprawdzie wybuchła w kilku krajach Europy Zachodniej i USA, ale miała też specyficzne podłoże w Polsce, Czechosłowacji i w Niemczech. Wzrost poparcia dla ruchów nacjonalistycznych (Pegida, Alternatywa dla Niemiec, Ruch Identytarystyczny) i głoszących rewizjonizm historyczny (Obywatele Rzeszy) to także renesans niekonwencjonalnych form protestu i demonstracyjnie okazywana niechęć wobec 
„systemu”. W takim kontekście uzasadnione wydają się pytania, czy obecne zjawiska nie oznaczają odrodzenia rewolucyjnego 1968 roku w skrajnie prawicowej formie ${ }^{6}$.

Próbę zmierzenia się z ówczesnym lewicowym radykalizmem i jednoczesnym przemilczaniem nazistowskiej przeszłości (w RFN rządził wówczas kanclerz Kurt Georg Kiesinger, przed 1945 rokiem działacz NSDAP) podjął Günter Grass, znany Polakom głównie z Blaszanego bębenka. W wydanej w 1969 roku powieści Miejscowe $z_{\text {znieczulenie }}^{7}$, mało rozpowszechnionej w Polsce, przedstawił metaforyczne ujęcia różnego rodzaju dolegliwości i prób ich leczenia. Chroniczny ból zębów trapi Eberharda Staruscha, nauczyciela w zachodnioberlińskim gimnazjum, który od dłuższego czasu poddaje się terapii stomatologicznej, sprowadzającej się do chwilowego uśmierzenia bólu. Prowadzi on rozmowy ze swoim uczniem o historii, współczesności i wynikającej z fanatyzmu przemocy. Jej skutkiem — niezależnie od motywacji ideologicznej z prawej lub lewej strony — jest zawsze cierpienie. W trakcie międzypokoleniowej dyskusji ujawnia się daleko posunięta ostrożność Staruscha, wynikająca z doświadczeń życiowych i wiedzy historycznej. Rewolucyjny zapał ogarnia natomiast jego ucznia, który relatywizuje pojęcie cierpienia i chce je zadać... swojemu jamnikowi. Podpalając go w miejscu publicznym, liczy na to, że skoncentrowany na konsumpcji, konserwatywny niemiecki mieszczuch dostrzeże $w$ akcie podpalenia psa tragedię ofiar amerykańskich nalotów z użyciem napalmu w Wietnamie.

Grass zapytany o tę powieść w programie TVP pod tytułem Dzieci kwiaty 19681972, powiedział:

Należałem wtedy do średniego pokolenia. Myśmy wtedy długo czekali, ażeby młode pokolenie zabrało głos. Właściwie życzono sobie tego na uniwersytetach niemieckich i nagle pojawiły się te ruchy, te protesty. Pamiętam, że starałem się wtedy ostrzec, iż celów wywodzących się z niemieckiego idealizmu, nie da się w nieskończoność propagować i na nowo interpretować. Tłumaczyłem to wielu organizatorom protestów. Poniekąd znajdowałem się między obozami ${ }^{8}$.

Mimo stosunkowo słabego odbioru w Niemczech (tym bardziej w Polsce), powieść Grassa wydaje się trafną, uniwersalną i wartą przypomnienia diagnozą, jakże aktualną w dobie ostrych podziałów społecznych i aktywizacji politycznej młodych ludzi, deklarujących jeszcze dekadę temu — i to w obu krajach — Politikverdrossenheit ('zniechęcenie polityką'), a obecnie szukających odpowiedzi na nurtujące ich pytania w radykalnych ugrupowaniach.

Günter Grass należał do wąskiego grona niemieckich twórców kultury, którzy często angażowali się w polskie sprawy, budząc ideologiczną czujność zarówno komunistycznych cenzorów, jak i osób literalnie rozumiejących patriotyzm. Z drugiej

${ }^{6}$ Por. m.in. A. Orzessek, „Linke APO, rechte APO”, Deutschlandfunk Kultur - Zeitfragen, 15.11.2017, http://www.deutschlandfunkkultur.de/kolumne-1968-und-die-neuen-rechten-linke-aporechteapo.976.de.html?dram:article_id=400748.

7 Por. G. Grass, Miejscowe znieczulenie, Gdańsk 1997.

8 M. Zakrocki, Dzieci kwiaty 1968-1972, Agencja Publicystyki i Edukacji dla Programu 1 TVP S.A. 2000. 
strony urodzony w Gdańsku noblista ochoczo występował jako instancja moralna i Praeceptor Germaniae: „Sposób, w jaki Niemcy z Zachodu obchodzą się z Niemcami ze Wschodu, to dla Polski rodzaj widowiska. Jeżeli oni ze sobą tak postępują, to jak będą się zachowywać w stosunku do nas, kiedy będą mieli wolne ręce? Oto pytanie, które można teraz zadać”. Czytając tę wypowiedź w 2020 roku, odczuwa się nieodpartą chęć doczytania jej dalszego ciągu w którymś z wydań „Gazety Polskiej”. Brzmi on następująco:

Nie boję się Europy. Krytykuję to, co się dzieje, czyli powiększające się biurokratyczne wodogłowie w Brukseli oraz fakt, iż Parlament Europejski staje się teatralny i nie jest w stanie konkurować z centralą. Gdyby się okazało, że w Europie powstają niedemokratyczne struktury — będę przeciw. Myślę, iż veto Duńczyków uwidoczniło wzięcie przez nich pod uwagę doświadczeń małego narodu i kierowanie się pewnym instynktem. Skrytykowali oni w porę niebezpieczeństwo stworzenia ogromnej administracji o ponadnarodowym zasięgu, wywierającym nacisk na Europę. Należy wziąć pod uwagę regionalne różnice. Rozwiązaniem byłyby tutaj elementy federalistyczne ${ }^{9}$.

To opinie, które autor niniejszego tekstu usłyszał w trakcie wywiadu z pisarzem w 1992 roku, kiedy jego wizja Polski zawarta w opowiadaniu Wróżby kumaka (mimo oczywistych przerysowań) odbiegała od obrazu kraju po 30 latach transformacji, a funkcjonowanie struktur europejskich wydawało się jedynie luksusowym dylematem bogatego Zachodu. W podobnym tonie jest utrzymana wypowiedź Grassa dla tygodnika „Wprost” z 1993 roku: „Wasze zaufanie do zachodnich polityków, którzy przyjeżdżają z dobrymi radami, idzie często zbyt daleko"10.

Noblista z Gdańska nie był jedynym niemieckim autorem, który - mimo jednoznacznie lewicowych sympatii - wygłaszał opinie, dziś mogące stać się przedmiotem manipulacji w prawicowych mediach — ich błyskawicznego rozwoju i znaczenia politycznego nie mógł wtedy przewidzieć. Hans Magnus Enzensberger jest kolejnym przykładem wybitnego twórcy i intelektualisty, w którego długiej (rocznik 1929) i barwnej biografii można odnaleźć zaangażowanie po stronie hipisowskiej Komuny I i działaczy opozycji parlamentarnej pokolenia '68. W późniejszym okresie swoją krytykę kierował z kolei pod adresem telewizji, mediów elektronicznych i struktur unijnych. W eseju Bruksela czy Europa - jedno $z$ dwóch, opublikowanym w przełomowym dla krajów bloku wschodniego roku 1989, Enzensberger nie szczędzi sarkazmu już od pierwszych słów swojego tekstu: „Na ideologicznym rynku narkotyków oferowany jest preparat pod nazwą Europa, jak gdyby był on amfetaminą lat dziewięćdziesiątych"11 , by stwierdzić w dalszym ciągu:

9 K. Okoński, „Jak postąpią z nami Niemcy? Rozmowa IKP-a z Günterem Grassem”, Ilustrowany Kurier Polski 1992, nr 243, s. 4.

10 W. Kot, „Skinheadzi w garniturach. Rozmowa z Günterem Grassem, pisarzem”, Wprost 1993, nr 2, s. 47.

11 H.M. Enzensberger, „Bruksela czy Europa - jedno z dwóch”, [w:] Europejskie wizje pisarzy niemieckich w XX wieku, wyb. i red. L. Żyliński, Poznań 2003, s. 262. 
Przypuszczam jednak, iż kolos brukselski stoi na glinianych nogach. Triumfalistyczna propaganda wspólnego rynku roku 1992 nie pozwoli przejść do porządku dziennego nad faktem, iż decyzje polityków podjęte zostały bez akceptacji społecznej ${ }^{12}$.

Dzisiejsze refleksje po lekturze dawnych pism Enzensbergera przybliża Christoph Cornelißen, analizując z perspektywy blisko trzydziestu lat tom Ach Europa!, będący plonem podróży niemieckiego poety po krajach Europy Zachodniej oraz pobytu w należących wówczas jeszcze do bloku wschodniego Polsce i Węgrzech. Przyglądając się życiu w PRL, Enzensberger z jednej strony skupia się na gospodarczych niedoborach, absurdach codzienności, wegetacji Polaków w blokowiskach, biurokracji, ale także na zrytualizowanym ludowym katolicyzmie i jego antymodernistycznych, czy wręcz opresyjnych praktykach. $Z$ drugiej strony odnotowuje przykłady oporu Polaków wobec niemieckiego okupanta i komunistów ${ }^{13}$ (wspomina między innymi morderstwo ks. Popiełuszki) oraz pisze z uznaniem o niewyobrażalnym wysiłku powojennej odbudowy. Odnosząc się z kolei do wrażeń z zachodnioeuropejskich peregrynacji i krytykując „łagodnego brukselskiego potwora” ${ }^{14}$, Enzensberger występuje — jak podkreśla autor poświęconego mu artykułu — w roli obrońcy wielokulturowego oblicza starej Europy. Jednocześnie pisarz staje w szeregu intelektualistów, którzy choć cenią różnorodność kulturową kontynentu, to równocześnie dostarczają lewicowej, a zwłaszcza prawicowej stronie sceny politycznej amunicji do niszczenia Unii Europejskiej ${ }^{15}$.

Grass i Enzensberger formułowali cytowane powyżej opinie w czasach dwutorowego rozwoju Europy - na Zachodzie skupionej na procesach integracji gospodarczej i politycznej, a na Wschodzie próbującej zagospodarować niedawno odzyskaną wolność po czterdziestu latach komunizmu. Integracja Polski z Zachodem, wzrost mobilności Polaków, procesy migracyjne, zniesienie kontroli granicznych na mocy układu z Schengen oraz rozłożenie na państwa UE zobowiązań związanych ze skutkami tak zwanego kryzysu uchodźczego coraz częściej konfrontują Polaków ze zjawiskami, które w Niemczech są elementem życia społecznego, politycznego i kulturalnego od ponad półwiecza.

Günter Wallraff jest pisarzem i reporterem, który swoją książką i filmem Na samym dnie (polska edycja 1988) wstrząsnął w 1985 roku zachodnioniemieckim społeczeństwem, przedstawiając ponury obraz życia tureckich gastarbeiterów w RFN i uświadamiając Niemcom, że pracę fizyczną, zazwyczaj w skandalicznych warunkach, wykonują coraz częściej pracownicy o obcych korzeniach. Obecność imigrantów wśród mieszkańców Republiki Federalneji ksenofobia czy wręcz neonazizm, z którymi są konfrontowani, stanowiły odtąd bardzo ważne aspekty twórczości

12 Ibidem, s. 266.

13 Tekst Enzensbergera „Polskie przypadki” ukazał się w drugoobiegowym czasopiśmie Akces 1989 , nr 2, s. 124-139.

14 Ch. Cornelißen, „Im Kampf gegen »Brüssel«. Zur Aktualität von Hans Magnus Enzensbergers »Ach Europa!« (1987)”, Zeithistorische Forschungen 2017, nr 1, s. 175.

15 Ibidem, s. 176. 
Wallraffa. Jednak autor nie pozostaje obojętny na nowe zjawiska wynikające $\mathrm{z}$ wielokulturowości i stanowiące zagrożenie dla wolności słowa w RFN. W 2007 roku podjął on mianowicie próbę zmierzenia się z radykalizmem islamskim na terenie Niemiec i wyraził chęć zorganizowania publicznego odczytu w kolońskim meczecie Szatańskich wersetów Salmana Rushdiego. Realizacja tego szeroko komentowanego projektu nie doszła jednak do skutku ze względu na groźby zabójstwa kierowane przez radykałów muzułmańskich pod adresem Wallraffa. DITIB, budząca wiele kontrowersji i jednocześnie wpływowa Turecko-Islamska Unia do Spraw Religijnych, postrzegana jako nieformalna emanacja państwa tureckiego i wylęgarnia radykałów religijnych, potępiła wprawdzie te pogróżki, lecz równocześnie z dużymi zastrzeżeniami zareagowała na propozycję prelekcji ${ }^{16}$. Do dyktowanych przez islamistów ograniczeń Wallraff odniósł się w stanowczy sposób: „To tak naprawdę papierek lakmusowy. Jeżeli odczyt się odbędzie, a postaram się, żeby tak było, to spowoduje on niezwykły katharsis"17. Podobne doświadczenia były także udziałem znanej w Niemczech socjolożki i autorki Necli Kelek: „Prezentacja mojej książki Die fremde Braut odbyła się w meczecie pod ochroną policji”. Znamienne jest jednak zakończenie cytowanego powyżej artykułu: „Mamy rok 2007 i zadajemy sobie pytanie, czy w Niemczech wolno organizować w meczecie publiczny odczyt książki” ${ }^{18}$.

Pomysł Wallraffa, autora o ogromnych zasługach dla dialogu interkulturowego w Niemczech, trudno uznać za prowokację wymierzoną przeciw żyjącym w RFN muzułmanom i ich religii. Mimo publicystycznych uproszczeń i stereotypów, jakie w swoim bestsellerze Niemcy. Samolikwidacja (2010) zawarł Thilo Sarrazin, członek zarządu Banku Centralnego RFN i Socjaldemokratycznej Partii Niemiec, określanie go mianem prowokatora lub wręcz rasisty — także w polskich mediach ${ }^{19}$ - również wydaje się nieuzasadnione. Jeszcze przed publikacją książki Sarrazin odniósł się do problemów $\mathrm{z}$ integracją imigrantów muzułmańskich, których stosunek do podstaw ustrojowych RFN najwyraźniej nie spędza snu z powiek działaczom DITIB: „Nie muszę akceptować kogoś, kto żyje na koszt państwa, odrzuca to państwo, nie troszczy się w rozsądny sposób o wykształcenie swoich dzieci i ciągle produkuje kolejne dziewczynki w muzułmańskich chustach" ${ }^{20}$. Zanim medialny ostracyzm spowodował przejście Sarrazina na radykalne pozycje (niezależnie od jego skłonności do samowiktymizacji), zyskał on poparcie nie tylko ze strony narodowych populistów (od czego zresztą się dystansował), lecz także od wybitnych osobistości życia politycznego i kulturalnego od wielu lat związanych z lewicą: byłego kanclerza Helmuta Schmidta

${ }^{16}$ M. Peters, „Nach Morddrohungen: Keine Wallraff-Lesung in Moschee”, Aachener Zeitung, 24.09.2007, https://www.aachener-zeitung.de/kultur/nach-morddrohungen-keine-wall.

17 H. Spiegel, „»Das ist ein echter Test «. Wallraffs Moschee-Lesung”, Frankfurter Allgemeine Zeitung 2007, nr 159, s. 33.

18 Ibidem.

19 Por. bart, „Bankier rasista dzieli SPD”, Gazeta Wyborcza, 26.04.2011, http://wyborcza. pl/1,75477,9498028,Bankier_rasista_dzieli_SPD.html.

20 V. Zastrow, „Kopftuchmädchen”, Frankfurter Allgemeine Zeitung, 3.10.2009, http://www.faz. net/artikel/C30089/kommentar-kopftuchmaedchen-30007531.html. 
(SPD) i reżysera (między innymi Blaszany bębenek, Strajk) Volkera Schlöndorffa: „On czyta w moich myślach. Podziwiam Sarrazina, wielokrotnie go odwiedzałem. Jako filmowiec jestem pod wrażeniem mocnych określeń" ${ }^{21}$.

Wzrost nastrojów nacjonalistycznych i antydemokratycznych w Europie, także w Niemczech, jest niezaprzeczalny i zwłaszcza w RFN budzi jednoznaczne skojarzenia z przeszłością. Z drugiej strony należy zadać pytanie o zdolność do autorefleksji sympatyków lewicy oraz o ich strategie rozrachunku z tymi zagrożeniami. Odnosząc ów dylemat do świata kultury i wiążąc go z wystąpieniami Sarrazina, można nawiązać na przykład do ideologicznych fascynacji Bertolta Brechta ustrojem dalekim od demokracji. Uczynił to w tygodniku „Die Welt” Matthias Heine, autor między innymi książki Verbrannte Wörter. Wo wir noch reden wie die Nazis - und wo nicht [Spalone słowa: kiedy jeszcze mówimy jak naziści - a kiedy już nie]: „Zawody z Thilo Sarrazinem o to, kto opowiada gorsze bzdury polityczne, wygrałby więc Brecht"22.

Pisząc z kolei o obecnych czasach, turecko-niemieckie dziennikarki berlińskiej lewicowej „Tageszeitung” ostrzegają bliskie im środowisko polityczne przed marginalizowaniem zagrożenia ze strony islamistów: „Milczenie i trywializowanie przez lewicę jest niebezpieczne, ponieważ z jednej strony pozostawia się zagadnienie islamizmu siłom reakcyjnym i ich narracji, a z drugiej ignoruje się ofiary, które na całym świecie zbiera polityczny islam. Islam jest częścią Niemiec, ale nie islamizm"23.

Spór o historię kolonialną Europy, formy wykluczenia na tle rasowym, kształt społeczeństwa wielokulturowego oraz granice wolności w sztuce przybrał formę, którą Daniel Kehlmann, popularny pisarz (i sygnatariusz listu 150 intelektualistów w sprawie obrony prawa do swobodnej debaty) streścił w krótkim zdaniu: „Przeżywamy właśnie rewolucję kulturalną" ${ }^{24}$. Rewolucja oznacza radykalne kroki w przypadku nazistów były nimi między innymi czystki w bibliotekach. Próba postawienia znaku równości między praktykami zbrodniczego reżimu a rozwiązaniami będącymi przedmiotem dyskusji w mediach wolnego kraju byłaby fundamentalnym nadużyciem, jednak w dobie obalania (nie zawsze zresztą godnych pamięci) pomników, nie unikniemy pytania o los książek:

${ }^{21} \mathrm{dpa} / \mathrm{AP} /$ fro, „Deutschland diskutiert über Sarrazin-Interview”, Merkur, 8.10.09, https://www. merkur.de/politik/deutschland-diskutiert-uebersarrazin-interview-488325.html.

${ }^{22}$ M. Heine, „Bertolt Brecht war schlimmer als Thilo Sarrazin”, Die Welt, 3.03.2014, https://www. welt.de/kultur/buehne-konzert/article125384495/Bertolt-Brecht-war-schlimmer-als-Thilo-Sarrazin. html.

23 R. Othmann, C. Sahin, „Gefährliches Schweigen. Linke und der politische Islam”, taz, 17.12.2019, https://taz.de/Linke-und-der-politische-Islam/!5646387/.

${ }^{24}$ S. Hammelehle, T. Rapp, „»Wir erleben gerade eine kulturelle Revolution«. Schriftsteller Daniel Kehlmann über Identitätspolitik. Ein Interview von Sebastian Hammelehle und Tobias Rapp", Spiegel Online, 10.07.2020, https://www.spiegel.de/kultur/daniel-kehlmann-zu-rassismus-protestenwir-erleben-gerade-eine-kulturelle-revolution-a-00000000-0002-0001-0000-000171973763.

Miscellanea Posttotalitariana Wratislaviensia 8, 2020

(C) for this edition by CNS 
Chcielibyśmy usunąć z bibliotek Richarda Wagnera? Był antysemitą. Mamy usunąć z nich wspomnienia Bismarcka? Był zdecydowanie antydemokratą. Ważne jest, aby postawić obok siebie różne modele służące wyjaśnianiu świata, wyrobić sobie o nich pogląd i zdekonstruować 25 .

W audycji rozgłośni Deutschlandradio, z której pochodzi powyższy cytat, przedstawiono dwie metody postępowania $\mathrm{z}$ takimi książkami: na uniwersytecie we Frankfurcie wydano tak zwany Faktencheck, zawierający krytyczną analizę informacji podanych w publikacji Thilo Sarrazina Wrogie przejęcie. Biblioteka Miejska w Duisburgu przyjęła natomiast radykalne rozwiązanie, usuwając ze swoich zasobów wszystkie książki niemiecko-tureckiego pisarza Akifa Pirinçci, znanego w ostatnich latach ze swoich kseno- i homofobicznych wystąpień. Likwidacja objęła także jego zdecydowanie apolityczne „kocie” kryminały, z których przez wiele lat słynął ${ }^{26}$.

Cóż w takim razie wolno satyrze? Słynne pytanie przedwojennego dziennikarza, satyryka i pisarza Kurta Tucholskiego można także odnieść do treści programów takich gwiazd niemieckiego stand-upu, jak Dieter Nuhr czy pochodząca z Austrii i mieszkająca w Niemczech Lisa Eckhart. Mierzą się oni z krytyką trudno porównywalną nawet $z$ oburzeniem (także w Polsce) po skeczach Haralda Schmidta, legendy niemieckich late night shows i tamtejszego odpowiednika Davida Lettermana.

Oddajmy zatem głos Nuhrowi: „Nasze dzieci wierzą w Gretę [Thunberg - K.O.] i noszą na ulicach jej wizerunek namalowany na tekturze. [...] Biedna dziewczyna. Już kilku biskupów porównało ją latem do Jezusa. Ale ona nie chodziła po wodzie, tylko potrzebowała żaglówki”. Nawiązując do słynnego „How dare you!” w wystąpieniu młodej aktywistki, Nuhr powiedział, że lepiej zrozumiałby zarzut o zniszczenie dzieciństwa, gdyby wypowiedział go dziewięciolatek pracujący w boliwijskiej kopalni wolframu ${ }^{27}$. Skutkiem tej wypowiedzi był internetowy shitstorm i żądanie usunięcia wypowiedzi Nuhra ze strony Niemieckiej Wspólnoty Badawczej (DFG). Była ona częścią kampanii „Dla wiedzy”, w której przedstawiciele środowisk akademickich i kulturalnych deklarowali poparcie dla naukowego podejścia do kluczowych problemów obecnej doby: zmian klimatycznych, pandemii koronawirusa, problemów demograficznych i digitalizacji. Nagranie Nuhra z takim przesłaniem zostało jednak ponownie umieszczone na stronie DFG, a artystę przeproszono. Filozof Philipp Hübl następująco podsumował kontrowersje wokół Dietera Nuhra: „Satyra jest dla naszej

25 A. Gerk, „Im Zweifel für die Meinungsfreiheit. Rechtspopulistische Bücher in Bibliotheken. Susanne Brandt und Hermann Rösch im Gespräch mit Andrea Gerk", Deutschlandfunk Kultur — Lesart, 3.01.2019, https://www.deutschlandfunkkultur.de/rechtspopulistische-buecher-in-bibliothekenim-zweifel-fuer.1270.de.html?dram:article_id=437353\&fbclid=IwAR0Z9NB-F274DNv8KgRmDhkD SgMA6qJ6uMQ8X7oZTvFNP8a2zz3nN5-Ljg4.

${ }^{26}$ Ibidem.

27 F. Naumann, „Dieter Nuhr attackiert Greta Thunberg schon wieder — und warnt vor »Krieg«”, Merkur, 30.12.2019, https://www.merkur.de/politik/greta-thunberg-dieter-nuhr-klimawandel-jahre srueckblick-krieg-kritik-zr-13360097.html. 
moralności rodzajem 'peer review' [...] Daje ona szansę przemyślenia naszego widzenia świata - podobnie jak nauka"28.

Sztandarowym przykładem współczesnej cancel culture jest jednak przypadek Lisy Eckhart. To pseudonim artystyczny Lisy Lasselsberger, dwudziestoośmioletniej gwiazdy slamu poetyckiego i kabaretu, która w krótkim czasie przeszła drogę od wielu nieudanych prób dostania się do szkół aktorskich do wielkiej popularności na scenie kabaretowej. Wyróżnia się nie tylko wizerunkiem stylizowanym na pin-up girl z lat pięćdziesiątych XX wieku, gestykulacją i długimi paznokciami, lecz również niekonwencjonalnym podejściem do tematów tabu, prezentowanych niegdyś przez Woody’ego Allena, gdy opowiadał dowcip o własnym ojcu, który sprzedał mu na łożu śmierci swój zegarek. W przypadku Allena żart wykorzystujący stereotyp na temat Żydów został przyjęty brawami i śmiechem. Eckhart wystąpiła w 2018 roku nie tylko w pierwszej osobie, ale również zapytała, czy ruch \#MeToo nie ma przypadkiem podłoża antysemickiego: „Weinstein, Allen, Polański... Żydzi! Najbardziej rozczarowani są Żydzi, którym zawsze zarzucano, że chodzi im tylko o pieniądze, a teraz nagle się okazuje, że tak naprawdę nie chodzi im o pieniądze. Im chodzi o baby i dlatego potrzebują pieniędzy!" 29 . Artystce ostatnio przypomniano to wystąpienie sprzed dwóch lat. Organizatorzy odbywającego się w Hamburgu Harbour Front Literaturfestival podjęli decyzję o usunięciu jej nazwiska z programu imprezy, lecz - jak podkreśla kierownik festiwalu Nikolaus Hansen — nie w ramach cenzury prewencyjnej. Jaki był zatem powód? Taki sam jak w przypadku Wallraffa próbującego zorganizować publiczne czytanie Szatańskich wersetów w meczecie: pogróżki - tym razem ze strony skrajnie lewicowego ${ }^{30}$ (tak określa ten ruch Krajowy Urząd Ochrony Konstytucji w Hesji) Czarnego Bloku. Z udziału w imprezie zrezygnowało także dwóch nieznanych z nazwiska autorów - unikając w ten sposób jakichkolwiek związków z artystką. Po stronie Eckhart, której uniemożliwiono odczyt jej debiutanckiej powieści Omama (piętnaste miejsce na liście bestsellerów tygodnika „Der Spiegel”), stanął znany niemiecki pisarz irańskiego pochodzenia Navid Kermani, odnosząc się do praktyki cancel culture: „[...] przeraża mnie sytuacja, w której jako pisarze zaczynamy się wzajemnie zakazywać"31.

28 P. Hübl, „»Satire ist eine Art Peer Review für unsere Moral«", Deutschlandfunk Kultur — Sein und Streit, 9.08.2020, https://www.deutschlandfunkkultur.de/philosoph-ueber-den-umgang-mit-dieter-nuhr-satire-ist-eine.2162.de.html?dram:article_id=481924.

${ }^{29}$ G. Haase-Hindenberg, „Rätselhafte Femme fatale. Gedanken zum Antisemitismusvorwurf gegen die Kabarettistin Lisa Eckhart", Jüdische Allgemeine, 14.05.2020, https://www.juedische-allgemeine.de/kultur/raetselhafte-femme-fatale/.

30 „Linksextremismus: Der »Schwarze Block «", Landesamt für Verfassungsschutz, https://lfv.hessen.de/extremismus/linksextremismus/erscheinungsshyformen/der-schwarze-block.

31 sha, „»Sie haben eine Kollegin zur Unperson gemacht«", Spiegel Online, 9.09.2020, https:// www.spiegel.de/kultur/literatur/lisa-eckhart-navid-kermani-verteidigt-kabarettistin-sie-haben-einekollegin-zur-unperson-erklaert-a-8674ead6-8d27-4c53-a269-e7811c7589a4.

Miscellanea Posttotalitariana Wratislaviensia 8, 2020

(C) for this edition by CNS 
Na pytanie prowadzącego program Aspekte w TV ZDF, czy aplauz ze złej, to znaczy skrajnie prawicowej, strony Eckhart uważa za efekt uboczny swoich występów, artystka odpowiedziała:

Nie uważam, żeby tak było w moim przypadku. Aplauz ze złej strony dostają raczej artyści, którzy unikają kontrowersji, ponieważ to właśnie oni nigdy nie wypowiadają się na tematy polityczne. Kiedy tylko pomyślę o tych budzących obrzydzenie prawicowych populistach, to już sama estetyka moich programów i mój sposób mówienia byłyby dla nich odpychające. Trudno mi sobie wyobrazić, żeby przychodzili je oglądać ${ }^{32}$.

Wśród artykułów poświęconych debacie wokół Eckhart, jakie pojawiły się na łamach „Jüdische Allgemeine”, gazety wydawanej przez Centralną Radę Żydów w Niemczech, można znaleźć także komentarz pt. Zagadkowa femme fatale. Przemyślenia na temat zarzutu antysemityzmu wobec artystki kabaretowej Lisy Eckhart. Jego autor przytoczył na wstępie historię wspomnianego skeczu Woody’ego Allena i zadał pytanie: „Czy ta puenta była antysemicka, czy też było to satyryczne podejście do antysemickiego stereotypu? Oczywiście to drugie i nikt nie zrozumiał tego źle”. W dalszej części artykułu autor formułuje ogólniejsze wnioski: „Od dawna występują u nas artyści kabaretowi, którzy zerwali z tradycją tej sceny. Niewielu z nich udało się pokazać coś naprawdę nowego, w każdym razie nie wtedy, gdy próbowali odnieść się do polityki, ponieważ gorset politycznej poprawności uciskał z każdej strony" ${ }^{33}$.

W telewizyjnej rozmowie z Eckhart wątek political correctness był zatem nie do uniknięcia:

Zdefiniowałabym polityczną poprawność jako nieco infantylną formę szacunku i grzeczności, która wymaga wyjątkowo sztywnych reguł i nie pozwala w danym momencie ocenić, co jest odpowiednie, a co nie. To mniej więcej tak, jakby mówić do dzieci, aby postępowały według określonego sposobu. Jeżeli je zapytać, dlaczego zachowują się tak, a nie inaczej, odpowiadają: ponieważ tak jest. One po prostu nie potrafią samodzielnie decydować, co robić, aby kogoś nie urazić3 ${ }^{34}$.

Radykalizacja nastrojów społecznych w warunkach obostrzeń wynikających z pandemii COVID-19 wydaje się nieuchronna i stanowi przez to spore wyzwanie dla wolności słowa.

Filozof Jürgen Habermas w następujący sposób odniósł się kondycji społeczeństwa i jego elit w obecnych czasach: „Jedno można powiedzieć: tak dużo wiedzy o naszej niewiedzy oraz o przymusie życia i działania w niepewności jeszcze nie było" ${ }^{35}$.

32 J. Schück, „Kabarettistin Lisa Eckhart im Gespräch mit Jo Schück über seltene Selbstschau, Publikum ohne guten Willen und Humor, der immer von oben auf die Dinge schaut", ZDF, 4.09.2020, https://www.zdf.de/kultur/aspekte/studio-gespraech-mit-lisa-eckhart-ueber-cancel-culture-100.html.

33 G. Haase-Hindenberg, op. cit.

${ }^{34}$ U. Welty, „»Ich lasse keine Religion und keine Ethnie aus «", Deutschlandfunk Kultur - Interview, 17.08.2020, https://www.deutschlandfunkkultur.de/lisa-eckhart-widerspricht-vorwuerfen-ichlasse-keine.1008.de.html?dram:article_id=482478.

35 T. Schmid, „Wenn der Geist versagt. Politik und Intellektuelle in Corona-Zeiten”, Die Welt, 1.05.2020, https://schmid.welt.de/2020/05/01/wenn-der-geist-versagt-politik-und-intellektuelle-incorona-zeiten/.

Miscellanea Posttotalitariana Wratislaviensia 8, 2020

(C) for this edition by CNS 
Pewności nie brakuje natomiast radykałom, za których sprawą ożywają demony przeszłości, teorie spiskowe oraz rośnie zagrożenie dla demokracji i otwartego modelu społeczeństwa. Taka wizja autorytarnych rządów w Niemczech pojawia się na kartach najnowszej powieści Magdaleny Parys, polskiej pisarki mieszkającej od 1984 w Berlinie. Książę ukazał się w czasie pandemii, a opublikowane przez Parys zapiski z berlińskich protestów przeciw antycovidowym obostrzeniom potwierdzają nie tylko jej obawy wyrażone w powieści, lecz mogą także posłużyć za współczesną ilustrację opisanej niegdyś przez Fromma „ucieczki od wolności”:

[...] powoli przywykam do tego, że obok ludzi zwyczajnie przegranych, złamanych i nieszczęśliwych po pandemii, bo naprawdę sporo stracili, albo zwyczajnie splajtowali, maszerują płaskoziemcy, antyszczepionkowcy, ezoterycy, skrajna lewica i skrajna prawica, wywrotowcy, antysystemowcy, anarchiści, nienawistnicy i zwykli brunatni, widziałam też tęczowe chorągiewki i Zielonych, i religijne zgrupowania pod krzyżem. Maszerują też zwykli obywatele, nasi sąsiedzi i sąsiedzi sąsiadów. [...] Jednak przy krzyczących trzydziestolatkach pod Ambasadą Rosji „Putin!”, „Putin!” w sensie, żeby ich i nas, i mnie, i ciebie, i Europę Putin wyzwolił - to jednak wysiadam, tym bardziej, gdy słyszę od brodatego młodzieńca, że rok '68 to nic, że rok '89 to nic, że upadek muru to też nic w porównaniu z tą demonstracją dzisiejszą wyzwolicielką antycovidową. I jeszcze dorzuca, że dyktatura NRD to w ogóle nie była taka straszna, jak ta dzisiejsza, bo ta NRDowska to była przynajmniej przejrzysta i jasna i każdy wiedział, że to dyktatura i co wolno a czego nie, natomiast ta dzisiejsza jest nieprzejrzysta i tym bardziej gorsza. Po czym znów krzyczy Putin, Putin żeby go wyratował z tych maseczek i innych kłopotów demokracji, tej samej, która umożliwia mu te krzyki, te marsze bez maseczki i brodę i piwo, które siorbie i samo demonstrowanie w sobie. (...) Właściwie gdy już byłam pewna, że to koniec, przez berliński tłum przemaszerował pochód Polski Walczącej, no i mówcie co chcecie, to jest sztos. Witali z miłością berlińczyków, Niemców i wszystkich dobrotliwym „dzień dobry, kochani”, a potem już tylko Reichstag szturmowali „Obywatele Rzeszy”, organizacja, której ideologia opiera się na prawicowym ekstremizmie, rasizmie i antysemityzmie, teoriach spiskowych i ezoterycznym światopoglądzie, nieuznającym państwowości RFN. Mają nawet swojego króla i kserowane na ksero paszporty. Twierdzą, że do dziś istnieje niemiecka Rzesza w granicach z 1937 r., która jest okupowana przez Aliantów i przez nich wyzyskiwana. Tak sobie pomyślałam nieśmiało, że się na pewno z Polską Walczącą zaprzyjaźnią ${ }^{36}$.

Artysta kabaretowy Florian Schroeder, decydując się na otwartą konfrontację z radykałami, których przy okazji antycovidowych demonstracji zjednoczyły antysystemowe hasła, wybrał strategię typową dla swojego rzemiosła - obnażył ich sposób myślenia, wykorzystując stosowaną przez nich narrację i jednocześnie nawiązując do języka nazistowskiej propagandy. Okazuje się, że mimo upływu lat wciąż jest to skuteczna metoda demaskowania odruchów charakterystycznych nie tylko dla pokolenia wojny, lecz także współczesnych populistów. W 1973 roku posłużył się tym zabiegiem znany wówczas komik Jonny Buchardt, wołając ze sceny podczas karnawału w Kolonii „hip, hip!", na co widzowie odpowiadali radosnym „hurra!”, aby po chwili rzucić w tłum okrzyk „Sieg!”, który sala gremialnie skwitowała słowem „Heil!”. Po chwili ciszy i z wyrazem zmieszania na twarzy Burchardt podszedł do mikrofonu mówiąc: „Niesamowite... Tylu dawnych towarzyszy pojawiło się

${ }^{36}$ M. Parys, wpis z 3.09.2020, godz. 15:04, https://www.facebook.com/parysmagdalena [zapis oryginalny].

Miscellanea Posttotalitariana Wratislaviensia 8, 2020

(C) for this edition by CNS 
tu dziś wieczorem!”37. O ile podobna prowokacja sceniczna blisko pięćdziesiąt lat temu mogła być skierowana do ludzi, którzy młodość spędzili w mundurach w kolorze feldgrau, to zbiorowy okrzyk „Tak!” tłumu antycovidowych demonstrantów w odpowiedzi na pytanie Schroedera: „Chcecie totalnej wolności słowa?” świadczył o ignorancji historycznej pokoleń urodzonych wiele lat po wojnie. Niemiecki komik sparafrazował bowiem przemówienie Josepha Goebbelsa z 18 lutego 1943, w którym minister propagandy III Rzeszy zwracał się do wiernej reżimowi publiczności, reagującej histerycznym „Tak!” na jego pytanie: „Chcecie wojny totalnej?”. Schroeder wykorzystał ten moment, by wygłosić krótkie przemówienie o konieczności przestrzegania zaleceń wirusologów, kończąc je wezwaniem: „Jeżeli jesteście za wolnością słowa, to musicie znieść także moje zdanie" ${ }^{\prime 3}$.

Niniejszy artykuł można zakończyć w duchu Kulturpessimismus, wskazując na kolejne zaskakujące zjawiska, które być może w przyszłości znajdą swój artystyczny wyraz w mowie wiązanej, na taśmie filmowej, w występach kabaretowych, utworach rockowych lub na kartach powieści i książek autobiograficznych: udział migrantów i Żydów w strukturach AfD (Hamed Abdel-Samad i Henryk Broder są pierwszymi prominentnymi gośćmi w tym gronie), homofobiczne, antyunijne, nierzadko wręcz wulgarne teksty i wypowiedzi turecko-niemieckiego pisarza Akifa Pirinçci, objęcie przywództwa ruchu antycovidowego i nawoływanie do rozprawy z rządem przez wychowanego w niemieckiej rodzinie Attilę Hildmanna, przejście na populistyczno-narodowe pozycje niektórych działaczy opozycji w byłej NRD czy artystów pop, głoszących ksenofobiczne hasła i kwestionujących suwerenność RFN (przykładem jest aktywność publiczna Xaviera Naidoo, popularnego piosenkarza soulowego o arabsko-hindusko-południowoafrykańskich korzeniach ${ }^{39}$.

Niewykluczone, że wspomniane zjawiska będą się nasilać w najbliższej przyszłości. Obserwując rozwój sytuacji w Niemczech i wyciągając wnioski co do polskiego życia kulturalnego i społecznego, warto przypomnieć refleksję Konstantego A. Jeleńskiego, zawartą w zakończeniu artykułu W poszukiwaniu utraconej wolności. „Kot” poświęcił go literaturze zachodnioniemieckiej, o której w 1954 roku można było pisać jedynie w prasie emigracyjnej, konkretnie na łamach paryskiej „Kultury”:

37 Jonny Buchardt - Auftritt Karneval, Köln 1973, https://www.youtube.com/watch?v=VUkgX4v-d-0.

38 Ch. Peitz, „»Wollt ihr die totale Meinungsfreiheit?« Der Kabarettist Florian Schroeder und sein dialektischer Auftritt auf einer Anti-Corona-Demo", Der Tagesspiegel, 10.08.2020, https://www. tagesspiegel.de/kultur/kabarettist-florian-schroeder-und-die-anti-corona-demo-wollt-ihr-die-totalemeinungsfreiheit/26079052.html.

39 O „migrantach prowadzących nagonkę na migrantów” pisze między innymi turecko-niemiecka publicystka Ferda Ataman, „Migranten, die gegen Migranten hetzen”, Spiegel Online, 17.09.2020, https://www.spiegel.de/politik/deutschland/selbsthass-bei-einwanderern-migranten-diegegen-migranten-hetzen-kommentar-a-8ea5b590-b381-475f-8399-593b2c7119f2?fbclid=IwAR10dr6 wpWuxe6yBsw5FtjROiQaYuluxR6FAVytTkGqLetVpzgFNsVM2YHU. 
Myślę znowu o książkach, które kiedyś pojawią się w Polsce. Czy pisarze nasi będą dążyć do socjologicznego wytłumaczenia własnej uległości fałszywemu mitowi? Czy będą się powoływać na to, że stał przy nich w tych latach duch Mickiewicza, Norwida? Czy będą może tworzyć polskich Szwejków, polskich kapitanów z Köpenick? Czy też potrafią, jak Böll i Andersch, znaleźć drogę do wolności we własnej psychice? ${ }^{40}$

\section{Bibliografia}

Ataman, Ferda. 2020. „Migranten, die gegen Migranten hetzen”, Spiegel Online, 17 września, https:// www.spiegel.de/politik/deutschland/selbsthass-bei-einwanderern-migranten-die-gegen-migranten-hetzen-kommentar-a-8ea5b590-b381-475f-8399-593b2c7119f2?fbclid=IwAR10dr6wpWuxe6yBsw5FtjROiQaYuluxR6FAVytTkGqLetVpzgFNsVM2YHU.

bart. 2011. „Bankier rasista dzieli SPD”, Gazeta Wyborcza, 26 kwietnia, http://wyborcza.pl/1,75477, 9498028,Bankier_rasista_dzieli_SPD.html.

Böll, Heinrich. 1982. „Ein neues Vokabolarium finden. Protokoll einer Pressekonferenz”. W: Verantwortlich für Polen?, red. Freimut Duve, Klaus Staeck, 9-17. Reinbek bei Hamburg: Rowohlt.

Buchardt, Jonny. Auftritt Karneval Köln 1973, https://www.youtube.com/watch?v=VUkgX4v-d-0.

Cornelißen, Christoph. 2017. „Im Kampf gegen »BRÜSSEL«. Zur Aktualität von Hans Magnus Enzensbergers »Ach Europa!« (1987)”, Zeithistorische Forschungen 1: 171-176.

dpa/AP/fro. 2009. „Deutschland diskutiert über Sarrazin-Interview”, Merkur, 8 października, https:// www.merkur.de/politik/deutschland-diskutiert-uebersarrazin-interview-488325.html.

Enzensberger, Hans M. 2001. „Bruksela czy Europa - jedno z dwóch ”. W: Europejskie wizje pisarzy niemieckich $w$ XX wieku, wyb. i red. Leszek Żyliński, 262-267. Poznań: Poznańska Biblioteka Niemiecka.

Enzensberger, Hans M. 1989. „Polskie przypadki”, Akces 2: 124-139.

Gerk, Andrea. 2019. „Im Zweifel für die Meinungsfreiheit. Rechtspopulistische Bücher in Bibliotheken. Susanne Brandt und Hermann Rösch im Gespräch mit Andrea Gerk", Deutschlandfunk Kultur - Lesart, 3 stycznia, https://www.deutschlandfunkkultur.de/rechtspopulistische-buecher-in-bibliotheken-im-zweifel-fuer.1270.de.html?dram:article_id=437353\&fbclid=IwAR0Z9NB-F274DNv8KgRmDhkDSgMA6qJ6uMQ8X7oZTvFNP8a2zz3nN5-Ljg4.

Graefe, Steffen. 2003. „Missachtung und Tabu. Eine Streitschrift zur Frage: Wie antisemitisch war die Gruppe 47?", Deutschlandfunk, 13 lutego, https://www.deutschlandfunk.de/missachtung-undtabu-eine-streitschrift-zur-frage-wie.700.de.html?dram:article_id=80782.

Grass, Günter. 1997. Miejscowe znieczulenie. Gdańsk: Wydawnictwo Polnord.

Hammelehle, Sebastian, i Tobias Rapp. 2020. „»Wir erleben gerade eine kulturelle Revolution«. Schriftsteller Daniel Kehlmann über Identitätspolitik. Ein Interview von Sebastian Hammelehle und Tobias Rapp", Spiegel Online, 10 lipca, https://www.spiegel.de/kultur/daniel-kehlmann-zu-rassismus-protesten-wir-erleben-gerade-eine-kulturelle-revolution-a-00000000-0002-0001-0000-000171973763.

Haase-Hindenberg, Gerhard. 2020. „Rätselhafte Femme fatale. Gedanken zum Antisemitismusvorwurf gegen die Kabarettistin Lisa Eckhart", Jüdische Allgemeine, 14 maja, https://www.juedische-allgemeine.de/kultur/raetselhafte-femme-fatale/.

Heine, Matthias. 2014. „Bertolt Brecht war schlimmer als Thilo Sarrazin”, Die Welt, 3 marca, https://www. welt.de/kultur/buehne-konzert/article125384495/Bertolt-Brecht-war-schlimmer-als-Thilo-Sarrazin. html.

Heine, Thomas T. 1927. „Sie tragen die Buchstaben der Firma-aber wer trägt den Geist?!”, Simplicissimus 51, strona tytułowa.

Hübl, Philipp. 2020. „»Satire ist eine Art Peer Review für unsere Moral «”, Deutschlandfunk Kultur — Sein und Streit, 9 sierpnia, https://www.deutschlandfunkkultur.de/philosoph-ueber-den-umgangmit-dieter-nuhr-satire-ist-eine.2162.de.html?dram:article_id=481924.

40 K.A. Jeleński, „W poszukiwaniu utraconej wolności”, Kultura 1954, nr 6, s. 125.

Miscellanea Posttotalitariana Wratislaviensia 8, 2020

(C) for this edition by CNS 
Jeleński, Konstanty A. 1954. „W poszukiwaniu utraconej wolności”, Kultura 6: 122-125.

Jonny Buchardt - Auftritt Karneval, Köln 1973, https://www.youtube.com/watch?v=VUkgX4v-d-0.

Kot, Wiesław. 1993. „Skinheadzi w garniturach. Rozmowa z Günterem Grassem, pisarzem”, Wprost 2: 46-47.

„Linksextremismus: Der »Schwarze Block «", Landesamt für Verfassungsschutz, https://lfv.hessen.de/ extremismus/linksextremismus/erscheinungsshyformen/der-schwarze-block.

Naumann, Florian. 2019. „Dieter Nuhr attackiert Greta Thunberg schon wieder — und warnt vor "Krieg«”, Merkur, 30 grudnia, https://www.merkur.de/politik/greta-thunberg-dieter-nuhr-klimawandel-jahresrueckblick-krieg-kritik-zr-13360097.html.

Okoński, Krzysztof. 1992. „Jak postąpią z nami Niemcy? Rozmowa IKP-a z Günterem Grassem”, Ilustrowany Kurier Polski 243: 4.

Orzessek, Arno. 2017. „Linke APO, rechte APO”, Deutschlandfunk Kultur - Zeitfragen, 15 listopada, http://www.deutschlandfunkkultur.de/kolumne-1968-und-die-neuen-rechten-linke-aporechteapo.976.de.html?dram:article_id=400748.

Othmann, Ronya, i Cemile Sahin. 2019. „Gefährliches Schweigen. Linke und der politische Islam”, taz, 17 grudnia, https://taz.de/Linke-und-der-politische-Islam/!5646387/.

Parys, Magdalena. 2020. Wpis z 3 września, godz. 15:04, https://www.facebook.com/parysmagdalena.

Peitz, Christiane. 2020. „»Wollt ihr die totale Meinungsfreiheit? « Der Kabarettist Florian Schroeder und sein dialektischer Auftritt auf einer Anti-Corona-Demo", Der Tagesspiegel, 10 sierpnia, https:// www.tagesspiegel.de/kultur/kabarettist-florian-schroeder-und-die-anti-corona-demo-wollt-ihrdie-totale-meinungsfreiheit/26079052.html.

Peters, Markus. 2007. „Nach Morddrohungen: Keine Wallraff-Lesung in Moschee”, Aachener Zeitung, 24 września, https://www.aachener-zeitung.de/kultur/nach-morddrohungen-keine-wall.

Schmid, Thomas. 2020. „Wenn der Geist versagt. Politik und Intellektuelle in Corona-Zeiten”, Die Welt, 1 maja, https://schmid.welt.de/2020/05/01/wenn-der-geist-versagt-politik-und-intellektuelle-incorona-zeiten/.

Schück, Jo. 2020. „Kabarettistin Lisa Eckhart im Gespräch mit Jo Schück über seltene Selbstschau, Publikum ohne guten Willen und Humor, der immer von oben auf die Dinge schaut", ZDF, 4 września, https://www.zdf.de/kultur/aspekte/studio-gespraech-mit-lisa-eckhart-ueber-cancel-culture-100. html.

sha. 2020. „»Sie haben eine Kollegin zur Unperson gemacht «", Spiegel Online, 9 września, https://www. spiegel.de/kultur/literatur/lisa-eckhart-navid-kermani-verteidigt-kabarettistin-sie-haben-einekollegin-zur-unperson-erklaert-a-8674ead6-8d27-4c53-a269-e7811c7589a4.

Spiegel, Hubert. 2007. „»Das ist ein echter Test«. Wallraffs Moschee-Lesung”, Frankfurter Allgemeine Zeitung 159: 33.

Thoß, Hendrik. 2008. Demokratie ohne Demokraten? Die Innenpolitik der Weimarer Republik. Berlin: be.bra verlag.

Welty, Ute. 2020. „»Ich lasse keine Religion und keine Ethnie aus«”, Deutschlandfunk Kultur — Interview, 17 sierpnia, https://www.deutschlandfunkkultur.de/lisa-eckhart-widerspricht-vorwuerfenich-lasse-keine.1008.de.html?dram:article_id=482478.

Wigura, Karolina. 2012. „Pokolenie pomocników artylerii. Habermas, Ratzinger, Luhmann i niemieckie spory", Stan Rzeczy 1 (2): 146-167.

Zakrocki, Maciej. 2000. Dzieci kwiaty 1968-1972. Agencja Publicystyki i Edukacji dla Programu 1 TVP S.A.

Zastrow, Volker. 2009. „Kopftuchmädchen”, Frankfurter Allgemeine Zeitung, 3 października, http:// www.faz.net/artikel/C30089/kommentar-kopftuchmaedchen-30007531.html.

Przyjęto do druku/Accepted for publication: 30.09 .2020

Miscellanea Posttotalitariana Wratislaviensia 8, 2020

(C) for this edition by CNS 